\title{
"Please consider my request for an interview": A Cross-cultural Genre Analysis of Cover Letters Written by Canadian and Taiwanese College Students
}

Hsiao-I Hou

In this study, similarities and differences among generic structures in 80 cover letters written by Taiwanese and Canadian college students were investigated, adopting Upton and Connor's (2001) framework. The results demonstrated that Canadian students tend to write longer letters, use a greater variety of word types and sentence structures, and choose more professional words than do Taiwanese students. From the moves-based analysis results, the study revealed that to achieve the main communicative purpose of a cover letter, which is to be contacted for an interview, the Canadians employed lengthy sentences and various strategies to demonstrate their qualifications. By contrast, Taiwanese students employed different communicative elements, including direct strategies to express their desire for an interview and uses of formulaic expressions that were not observed in the Canadian corpus. The research findings suggest that the movestructural and rhetorical differences are due to writers' differences in cultural backgrounds and their rhetorical and lexical knowledge of the particular genre. The results of this study provide implications for teaching English for specific purposes to nonnative speakers.

Cette étude a porté sur les ressemblances et les différences des structures génériques dans 80 lettres de motivation écrites par des étudiants de Taïwan et du Canada, et s'est appuyée sur le cadre de Upton et Connor (2001). Les résultats ont démontré que les étudiants canadiens tendent à écrire des lettres plus longues, à employer des mots de nature plus diverse et des structures de phrases plus variées et à choisir davantage de mots professionnels que les étudiants de Tä̈wan. Les résultats d'une analyse de corpus ont révélé que pour atteindre l'objectif communicatif principal d'une lettre de motivation, soit d'être contacté pour une entrevue, les Canadiens ont eu recours à des phrases très longues et à diverses stratégies pour faire connaitre leurs qualifications. En revanche, les étudiants de Taïwan ont employé des éléments de communication différents, y compris des stratégies directes pour exprimer leur désir de se voir accorder une entrevue et des expressions préétablies pas repérées dans le corpus canadien. Les résultats de la recherche portent à croire que les différences structurales et rhétoriques sont dues aux différences dans les antécédents culturels des étudiants et dans leurs connaissances rhétoriques et lexicales du genre en question. Ces conclusions ont des conséquences pour l'enseignement de l'anglais à des fins particulières à des locuteurs non-natifs. 


\section{Introduction}

Because of increasing trends in international student mobility and the establishment of various study-abroad programs, students can now travel to a foreign country to study, conduct research, or join the local workforce in an internship opportunity. When attempting to integrate into their new environment, international and exchange students are challenged to understand the specific functions of a particular genre in a foreign country (Taillefer, 2005). Reichelt, Lefkowitz, Rinnert, and Schultz (2012) described the common assumption of students of English as a foreign language (EFL) that writing well in the target language simply involves learning appropriate vocabulary and grammar, and then applying this knowledge in English composition. Foreign language writing is far more complex than translation or learning formats (Friedlander, 1990). Cognitive matters involving culture, assumptions about foreign language (FL) writing tasks, and the influence of high-level thinking in the native language all complicate FL writing tasks (Reichelt, 2011).

Genre also plays various roles in different cultural contexts (Bhatia, 1993). For example, cover letters in Western business environments typically involve the component of self-appraisal. Certain studies have shown that this component is unfamiliar to Flemish students (Connor, Davis, \& De Rycker, 1995), French students (Jenkins \& Hinds, 1987), Indian students (Bhatia, 1993), and Arabic students (Al-Ali, 2004, 2006). Meeting the communication needs of people throughout the business world is even more complex. A major body of emerging research indicates that readers and writers think and interpret differently in different languages (Friedlander, 1990; Reichelt, 2011). Therefore, lack of regard for the sociopragmatic and generic functional aspects of language leads to severe communication problems.

The main communicative purpose of a cover letter is "to elicit a specific response from its reader(s)" (Bhatia, 1993, p. 59), or to create a desire in the prospective employer to hire the job applicant (Brusaw, Alred, \& Oliu, 1987). According to Bhatia (1993), sociocultural factors in certain contexts influence certain types of professional genres. As Connor (2004) states, genre expectation varies from culture to culture; therefore, a job application letter, which is a professional genre, may also vary in style in different parts of the world. Based on a review of the literature, no study has been conducted that investigates Taiwanese student cover letter writing in English. In addition, documents considered essential when applying for jobs or internships in Taiwan's business community are a résumé and a brief autobiography, but not a cover letter. According to an online survey conducted in Taiwan, 59\% of employers do not request a cover letter in a job application (51 Job News, 2010). For Taiwanese exchange students who expect to pursue an overseas internship opportunity in an English-speaking country, an impressive English cover letter is indispensable. Because these students are not familiar with this genre and do not understand the normative purpose and function of cover letters 
in the Western business community, how they accomplish the task of writing an effective cover letter is worthy of investigation.

Thus the primary aim of this research is to examine the cross-cultural similarities and differences of linguistic features in internship cover letters written by Taiwanese and Canadian college students majoring in hospitality management studies. For hospitality majors, an internship is a major component of the curriculum. The internship placement process, however, is challenging for many international students. During the process, they must exhibit strong written communication skills when producing cover letters and résumés, and they must demonstrate strong oral communication skills in interviews. By employing genre analysis to examine how component moves constitute an effective cover letter, we hope that the study results may yield insights into nonnative speakers and their communicative skills in native-English environments. In addition, the results may help foreign language teachers to increase student awareness of the essential genre-specific requirements to produce effective written forms of communication and avoid communication failure.

\section{Literature Review}

To satisfy the research goals, literature related to topics of contrastive rhetorical analysis and business cover letter writing are reviewed. The theoretical framework for this study is also presented.

\section{Contrastive Rhetorical Analysis}

Kaplan's (1966) early argument in contrastive rhetoric states that every culture develops its distinctive patterns of thinking and that these patterns considerably influence the organizational structure of writing. Kaplan's original proposal became an influential framework for early rhetoric studies that focused mainly on contrastive analysis, error analysis, and the idea of a first language (L1) influencing second-language (L2) learning. Later studies (Atkinson, 1999; Flower \& Hayes, 1981; Mohan \& Lo, 1985; Scollon, 1997; Spack, 1997; Zamel, 1997) determined that Kaplan's proposal was insufficient in explaining the organizational features of L2 writing. They identified such insufficiencies as ignoring the writer's writing process, simplifying the nature of the organization of a particular language or culture, misinterpreting the organizational structure of certain languages or cultures, being insensitive to cultural differences, and overlooking individual differences in cultural matters.

Recently, developments in contrastive rhetoric have expanded not only basic topics in English as a second language (ESL) and EFL fields but also in the fields of English for specific purposes (ESP) and English for academic purposes (EAP) to include additional cross-cultural discussions. Some researchers believe that dismissing the role of the cultural, linguistic, and edu- 
cational background of language learners could lead to cultural stereotyping by teachers and fellow students (Connor, 2004). Certain researchers (Belcher \& Connor, 2001; Kroll, 2003; Matsuda, 2006) proposed reexamining the underlying assumptions and revising the research methods. Connor's (2004) historical review of contrastive rhetoric studied over the past 30 years concluded that the subject has moved toward a context-sensitive research approach that includes studying the social context, local situatedness, writing process, the written products themselves, and the history and social structures of a particular culture. In a later study, Connor (2008) proposed the term intercultural rhetoric to replace contrastive rhetoric to better reflect interpersonal and intercultural influences on writing and to better understand the relationship between cultures and approaches to and styles of writing. Contrastive rhetoric and intercultural rhetoric have been extensively adopted in teaching business and technical writing (Al-Ali, 2004, 2006; Bhatia, 1993; Connor et al., 1995; Upton \& Connor, 2001). Researchers in this field have advocated that cultural differences be explicitly taught to acculturate EFL writers to the target community (Swales, 2004). In other words, EFL and ESP teachers must educate students about readers' expectations.

\section{Cover Letters in Business Writing}

Business writing is a type of literary activity that possesses a special communicative purpose and employs a particular format and lexicon. Cover letter writing for job or internship applications is part of the business writing genre. It not only serves as a communication medium, but it also reflects the professional image of the writer and his or her personal characteristics and background. Appropriate word usage, sentence construction, organization, and style contribute to both the professional and personal quality of a cover letter (Al-Ali, 2004; Bhatia, 1993).

Previous studies have not sufficiently examined the genre of cover letters. Bhatia (1993) first identified cover letters as a specific genre in business writing. He analyzed job-application letters and sales promotion letters by using schematic structural analyses, and he examined the similarities of these two types of text with regard to communicative purposes and move patterns. His studies also revealed the differing roles and communicative purposes of cover letters in India and America. Connor et al. (1995) demonstrated that Flemish students resembled the Indian group studied by Bhatia (1993) in that Flemish students did not use the cover letter as an instrument of selfpromotion. These researchers explained that a lack of self-promotion in cover letters is related to the power distance between the writer and the reader.

Upton and Connor (2001) later identified cross-cultural differences that possibly influence the effectiveness of application letters written by American and European undergraduate students by analyzing a corpus covering a 10-year period. Their study concluded that the style of application letters 
has become increasingly homogenized in the global business environment. Henry and Roseberry (2001) used 40 application letters to analyze writing strategies from another perspective. Their study revealed a wide range of discourse and linguistic features in a single genre move. Al-Ali (2006) demonstrated that Arabic-English bilingual writers do not use politeness strategies in their cover letters because they are unaware of sociocultural constraints. Hou and Li (2011) examined the surface linguistic features of cover letters by using cross-cultural analysis and revealed that student rhetorical knowledge of a specific genre and sociocultural factors influence the writing strategies that students employ.

The findings from the aforementioned studies show that analyses are shaped and constrained by cultural differences despite members of a particular discourse community sharing the same communicative purposes. In addition, these studies have shown that sociocultural issues transfer to writer consciousness, resulting in differences in writing styles and the adoption of different writing strategies. Henry and Roseberry (2001) ignored the sociocultural context in their analysis and demonstrated only how a corpus analysis can be a useful tool for EFL instructors. Certain studies have not used real writing samples but rather hypothetical ones, which can generate bias and analytical errors during analysis.

\section{Theoretical Framework}

The goal of the present study is to identify the similarities and differences in genre components among cover letters written by Taiwanese and Canadian hospitality students. A moves-based analysis is applied to genre-specific learner corpora. This study builds on earlier studies by adopting Upton and Connor's (2001) move-structure analysis on a corpus of job application letters written by American and European undergraduates. Their framework was developed from Swales's (1990) ideas about discourse communities and Bhatia's (1993) move analysis.

Swales (1990) explains that discourse communities are sociorhetorical networks that are created to achieve common objectives. The members of this community are familiarized with the particular genres that are used to achieve the stated goals. Therefore, genres belong to discourse communities and not to individuals, other types of groups, or to wider speech communities. Bhatia (1993) provided a comprehensive review of his own studies from the 1980s and employed discourse analysis to examine legislative and business writing. According to Bhatia (1993), "specialist writers seem to be fairly consistent in the way they organize their overall message in a particular genre, and analysis of structural organization of the genre reveals preferred ways of communicating intention in specific areas of enquiry" (p. 29). Bhatia provided several examples of genres used in professional settings, such as sales promotion letters and job applications, to illustrate the move structure 
of these genres. These analyses identify the same move structures across the textualizations of individual genres, according to the genre's communicative purpose, and they describe variations in the move structure that occur in different genres.

Upton and Connor (2001) proposed a revised framework based on a study by Connor et al. (1995) that analyzed application letters written by college students in Belgium, Finland, and the United States. Seven move structures are provided in Upton and Connor's framework: (a) identifying the source of information, (b) applying for the position, (c) providing argument, (d) indicating desire, (e) expressing politeness, (f) offering to provide more information, and (g) referencing an attached résumé (p. 318). By applying this framework to analyze the corpus of hypothetical application letters, Upton and Connor (2001) revealed that the Americans tended to employ a more patterned style, the Belgians exhibited more individuality in their letters, and the Finns fell between the Belgians and the Americans in writing style. The researchers also suggested that the level of language proficiency of students and the nature and type of language instruction provided to them should be considered when contrastive rhetorical analysis is conducted.

Two research questions were employed in the study:

1. What types of linguistic strategies are employed by novice writers in Taiwanese and Canadian cover letters?

2. How do cultural factors affect Taiwanese and Canadian novice cover letter writing?

\section{Methodology}

\section{Participants}

Eighty English cover letters were collected for analysis in this study, 40 of which were written by college exchange students from Taiwan and the other 40 of which were written by Canadian college students. These 80 students attended public colleges in Canada and majored in hospitality-related fields, including hospitality management, culinary arts, and travel management. Although the native language of the Taiwanese writers was Mandarin, they had received at least 7 years of formal instruction in English at both the secondary school and college levels in Taiwan. For Taiwanese students to qualify as exchange students in Canada, they must attain a score of 520 or higher on the Test of English for International Communication. These students lived in Toronto as exchange students and enrolled at a public college for 1 year. After arriving in Canada, they attended an advanced summer immersion ESL program in July, then took two semesters of hospitality-related courses in English. From May to September, they worked as paid interns in hospitalityrelated environments such as hotels, resorts, and restaurants in Canada. 
All letters were written by applicants who secured internship positions in Canada. Both groups of Canadian and Taiwanese students were required to enroll in a career development course during their first semester in college to examine career choices in the Canadian hospitality industry and to prepare for internships in the field. Students developed skills in cover letter and résumé writing, interviewing, and job search techniques; determined career goals; and learned other professional skills required to succeed in the course. In the following semester, they began the internship-placement process through assistance from the internship office and the job portal website at the colleges they attended.

\section{Data Analysis}

As previously mentioned, the study adopted the framework of Upton and Connor (2001) to identify the rhetorical features of the genre examined in this study. Some of the moves in their model did not apply to this study's data. Thus it was necessary to modify their categories to meet the variations seen in the corpora. Table 1 provides a description of the modified framework and the code for each move. The minor modifications involve deleting Move 6 ("offer to provide more information") and Move 7 ("reference attached résumé") from Upton and Connor's model (2001, p. 318). In addition, Move 2 is divided into two subcategories-(a) using a direct strategy and (b) using an indirect strategy - when the applicant states the position for which they are applying. This coding scheme is more suitable and feasible than that employed by Upton and Connor for comparing the moves in the internship cover letters of novices. In addition, it reflects the information structure of this genre.

Table 1

Description of the Move Structure and Codes for the Present Study

\begin{tabular}{lll}
\hline & Move Description & Code \\
\hline 1 & Identify source of information & M1 \\
2 & a: Apply for the position-direct strategy & M2a \\
& b: Apply for the position-indirect strategy & M2b \\
3 & $\begin{array}{l}\text { a: Provide arguments - general background and experience information } \\
\text { b. Provide argument-good for the hiring company }\end{array}$ & M3a \\
& c. Provide argument-good for the applicant & M3b \\
4 & Desire for interview or further contact & M3c \\
5 & Express politeness or appreciation & M4 \\
\hline
\end{tabular}

All names and any other information that might identify an applicant or the institution receiving an application were removed. All sample letters were scanned and converted to computer files. The treatment of data generally followed the clean-text policy used by Sinclair (1991), a process in which codes 
are removed to keep the text unprocessed and clean. Two English instructors were invited to participate in this study as raters. Using the aforementioned coding scheme, the T-units of each letter were coded by the researcher and the two English instructors. The raters were asked to focus on the existence of the move and not on the order. The three raters possessed an agreement rate of $87 \%$ on identifying and categorizing the moves on $30(37.5 \%)$ randomly selected letters, thereby establishing interrater reliability. Quantitative analyses of linguistic features, including sentence length, lexical density, and move analyses, were conducted by calculating the frequencies of tokens, Tunits, and moves. To satisfy the research purposes, SPSS 14.0, VocabProfile 3.0 (Lexical Tutor), and AntConc were used to analyze the linguistic features of the collected cover letters by country.

\section{Results}

To provide detailed illustrations and answers to the research questions, the results are presented in the following sequence. First, we discuss all surface linguistic features and the move analysis used in the study, including move occurrences, frequencies, and move patterns. We then present the individual component moves by describing examples from the corpus, thus providing a detailed examination of cover letters.

\section{Surface Features of the Corpus and the Letters}

The corpora in this study comprised 40 internship cover letters written by Canadian college students and 40 cover letters written by Taiwanese exchange students, totaling 16,229 words. Table 2 provides a summary of the length of all 80 letters. The average length for the entire group of 80 letters was 196 words. The average length of letters written by Taiwanese students was 191 words, the longest was 242 words, and the shortest was 156 words. Among Canadian students, the respective lengths were 215, 314, and 159. The $t$-test value revealed that the difference in the mean length of cover letters was statistically significant, $t(79)=.782, p=0.003$. The Taiwanese samples revealed a lower lexical density (52\%) than the Canadians' $(54 \%)$, but the difference was not significant.

The aforementioned data demonstrate that Canadian students tended to write longer cover letters than did their Taiwanese counterparts. The length variance of cover letters for Canadian students was also greater than that for Taiwanese students, and Canadian students used more variables related to lexical density and structural complexity. The results resemble the results of studies by Bhatia (1993) and Connor et al. (1995) in which cross-cultural analyses were conducted on cover letters written by native and nonnative speakers. 
Table 2

Length of Cover Letters Written by

Taiwanese and Canadian College Students

\begin{tabular}{lrrrr}
\hline Students & Total words & $M$ & $S D$ & Lexical density \\
\hline Taiwanese & 7,640 & 191.00 & 25.04 & $52.12 \%$ \\
Canadian & 8,589 & 214.73 & 42.72 & $54.66 \%$ \\
Total & 16,229 & 195.57 & 36.78 & \\
\hline
\end{tabular}

Lexical knowledge, word usage, and range of vocabulary reflected in various types of writing should be analyzed when student writing is assessed. After we evaluated the Taiwanese and Canadian corpora using VocabProfile 3.0, the vocabulary characteristics of each corpus were identified. A comparison of Taiwanese and Canadian cover letters revealed that Canadians used a greater number of different word types (983) than did their Taiwanese counterparts (771). Canadian students used slightly more of the first 2,000 frequently used English words (84.17\%) than did their Taiwanese counterparts $(83.45 \%)$ in their cover letter writing. They also used more words $(5.74 \%)$ from A New Academic Word List (Coxhead, 2000) than did the Taiwanese students $(4.11 \%)$. The Taiwanese used unlisted words $(12.43 \%)$ more than their Canadian counterparts did (10.10\%). The data reveal that Canadian students possessed a wider spectrum of word choice, and used more professional and fewer unfamiliar words than the Taiwanese students did. One possible explanation for these differences is that Canadian students are aware of the importance placed on quality cover letters and use cover letters as formal tools of self-promotion. They thus attempt to impress their knowledge, experience, and professionalism on the potential employer and tend to use more advanced words than their Taiwanese counterparts do. However, the English proficiency of Taiwanese students is not at a native level, which limits their word usage in formal writing. It was also demonstrated that Taiwanese students used more proper names than the Canadian students did to explain their life experiences, and they employed a higher percentage of off-list words in their writing.

Table 3 reveals considerable variation in the occurrence and length of move components between Canadian and Taiwanese cover letters. With regard to certain moves, including M1, M2b, M3b, M3c, and M5, Taiwanese students produced shorter components than their Canadian counterparts did. With respect to move M3a, Taiwanese students used a greater number of words to describe their background and experience than their Canadian counterparts did. The length differences in this move are statistically significant. For moves M3b, M3c, and M5, Canadian students used more words to express the receptive meaning of components. The length differences in those moves are also statistically significant. When establishing their credentials, the Taiwanese students only introduced their background and previous 
work experience, unlike their Canadian counterparts, who employed different strategies when providing their qualifications or when explaining how both parties would benefit if the applicant was hired.

Table 3

Codes, Mean Number, and Standard Deviations of Words in Each Move

\begin{tabular}{|c|c|c|c|c|c|c|}
\hline \multirow[b]{2}{*}{ Move Components } & \multirow[t]{2}{*}{ Code } & \multicolumn{2}{|c|}{ Taiwanese } & \multicolumn{2}{|c|}{ Canadian } & \multirow[b]{2}{*}{$F$} \\
\hline & & $M$ & $S D$ & $M$ & $S D$ & \\
\hline 1: Identify source of information & M1 & 7.45 & 5.62 & 9.25 & 8.39 & 1.79 \\
\hline $\begin{array}{l}\text { 2-a: Apply for the position- } \\
\text { direct strategy }\end{array}$ & $\mathrm{M} 2 \mathrm{a}$ & 6.8 & 10.03 & 4.1 & 7.16 & 2.32 \\
\hline $\begin{array}{l}\text { 2-b: Apply for the position- } \\
\text { indirect strategy }\end{array}$ & $\mathrm{M} 2 \mathrm{~b}$ & 26.48 & 18.82 & 30.8 & 16.87 & 0.82 \\
\hline $\begin{array}{l}\text { 3-a: Provide arguments- } \\
\text { general background, experience } \\
\text { information }\end{array}$ & М3а & 98.58 & 26.61 & 82.9 & 36.59 & $6.85^{\star}$ \\
\hline $\begin{array}{l}\text { 3-b. Provide argument-good for } \\
\text { the hiring company }\end{array}$ & M3b & 4.55 & 9.42 & 26.88 & 27.31 & $31.33^{* * *}$ \\
\hline $\begin{array}{l}\text { 3-c. Provide argument-good for } \\
\text { the applicant }\end{array}$ & M3c & 1.23 & 4.62 & 8.05 & 18.62 & $6.38^{*}$ \\
\hline $\begin{array}{l}\text { 4. Desire for interview or further } \\
\text { contact }\end{array}$ & M4 & 36.75 & 22.50 & 29.8 & 14.33 & 2.89 \\
\hline $\begin{array}{l}\text { 5. Express politeness or } \\
\text { appreciation }\end{array}$ & M5 & 5.98 & 5.20 & 15.75 & 6.09 & $68.79^{* * *}$ \\
\hline
\end{tabular}

${ }^{\star} p<.05 ;{ }^{* \star *} p<.001$

Based on AntConc analysis, the three most frequent moves Taiwanese students employed in their cover letters were M3a, M4, and M2b. For Canadian students, the top three moves were the same but in a different order: M3a, M2b, and M4. Without the moves of applying for the position (M2a or M2b), providing supporting information for the application (M3a), and indicating a desire for an interview (M4), a cover letter cannot be identified as effective. These moves appear in every letter, are by far the longest of the moves examined, and occur more than once. Therefore, they can be identified as required moves. Although the move M1 can be identified as optional, it appeared in 23 letters (57.5\%) of the Taiwanese corpus and 29 letters $(72.5 \%)$ of the Canadian corpus. Move M5 shows appreciation, but 11 letters (27.5\%) in the Taiwanese samples did not possess this move, whereas all Canadians used this move. Moves M5 and M4 typically appear in the last paragraph of the letter. Taiwanese students likely placed too much emphasis on revealing their desire for interviews or providing contact information, but forgot or did not know how to express gratitude at the end of the letter. Consequently, they wrote more words in the M4 move than in the M5 move. 


\section{The Move Structures of Cover Letters}

We now explain individual moves in greater detail by examining sample sentences elicited from the corpora.

\section{M1: Identifying Sources of Information}

The purpose of this move is to include references to sources of job information and to establish credentials of applicants as revealed in their cover letters when they referred to the needs of the employer (Al-Ali, 2006). As previously mentioned, this move did not appear in every letter, but it was in $72.5 \%$ of the Canadian cover letters and in only $57.5 \%$ of the Taiwanese cover letters. Neither group employed long sentences or phrases to demonstrate this move. The reason for this could be that both groups of novices, particularly Taiwanese students, were unfamiliar with the functions of this move. Therefore, they either skipped this move or simply forgot to refer to their source of job information.

The examples that follow are extracted from the corpora used in this study.

1. I saw the housekeeping position which was posted by XXX. (Taiwanese $\# 13$ )

2. I heard the summer work experience program opportunities on campus. (Taiwanese \#34)

3. I am responding to your ad on the internet on www.xxx.ca. (Canadian \#6)

4. I saw your advertisement for prep/line cook position at your restaurant from the website posted on October 7 2011. (Canadian \#24)

\section{M2a and M2b: Applying for the Position}

In this move, the writers must clearly state the position for which they are applying. The data show that all the samples employed this move in their letters and used different strategies to do so. The Canadian students used more words to describe the particular position they were applying for and stated their enthusiasm and qualifications for the position. They used the third-person subject to express their personal interests in particular positions or combined their interests with other sentences and phrases to express their enthusiasm, which were indirect strategies. By contrast, most of the Taiwanese students expressed their interests in particular positions in a single sentence or by beginning the sentence with a first-person pronoun. In addition, whereas the Canadian students expressed their intentions for the position by describing their "interests" (Examples 7 and 8), the Taiwanese students directly stated their intentions by using verbs such as "look for" or "apply" (Examples 5 and 6). This indicates that Taiwanese students use direct strategies to state their intentions, whereas their Canadian counterparts use an indirect strategy to describe their intentions. The following examples help to illustrate this discovery. 
1. I am current looking for a possible job opportunity as a chef in your kitchen. (Taiwanese \#6)

2. I am writing to apply for the position of catering manager at XXX. (Taiwanese \#17)

3. This letter is to express my interest in kitchen chef. (Canadian \#22)

4. This cook position is of great interest to me as I am currently pursuing a career in the culinary arts. (Canadian \#15)

\section{M3a, M3b, and M3c: Provide Arguments}

The purpose of this move is to present the relevant ability of the applicants for the particular position. This move can be employed using three substrategies, including providing general background and experience information (M3a), explaining the benefits to the company after candidates are hired $(\mathrm{M} 3 \mathrm{~b})$, and stating the benefits to the candidates after they are hired (M3c). The data reveal that in both corpora this move occurs (100\%) by integrating different strategies. In the Taiwanese corpus, only 8 samples $(20 \%)$ used the M3b strategy and only 2 samples (5\%) adopted the M3c strategy. One possible explanation is that Taiwanese students are unfamiliar with the M3b and M3c strategies. As previously mentioned, a brief autobiography is essential for a job application in the Taiwanese business community. Therefore, the Taiwanese students strongly emphasized their academic background and previous experience by incorporating M3a in their cover letters. In the Canadian corpus, 27 sample letters (67.5\%) employed M3b and 15 letters(37.5\%) used M3c. Apparently, Canadian students are more familiar with the functions of M3b and M3c in cover letters than their Taiwanese counterparts are. Another possible explanation is related to differing cultural views about selfappraisal. Several studies have shown that when writing about themselves, a greater number of East Asians, particularly Japanese and Chinese, appraise themselves in a less favourable way than their Western counterparts (e.g., Canadians, Americans, and Britons) do, because they are self-critical regarding assessments of private dimensions (Kurman, 2001; Sedikides, Gaertner, \& Toguchi, 2003). Therefore, Taiwanese students are less likely to promote themselves in cover letters by adopting Moves $3 b$ and $3 c$. They simply state their educational or work backgrounds as evidence to support their qualification for the position. The following examples from cover letters illustrate the differences between the Canadian and Taiwanese writers in this regard.

9. I study hotel management in Taiwan, and I have internship experience in school's hotel. (Taiwanese \#3)

10. I am currently enrolled in the hospitality and hotel management program at XXX college. (Taiwanese \#19)

11. I believe that I will be the best person for this job because I have got some experience behind me from my school. (Canadian \#12)

12. I am confident that my skills of being able to take criticism and learn from it will help me become a better chef and be a better employee. (Canadian \#17) 


\section{M4: Desire for Interview or Further Contact}

As explained by Al-Ali (2006), expressing desire for an interview or followup contact between the applicant and the prospective employer may yield an invitation for additional correspondence, perhaps to answer questions from either party. This move is considered by most professional writers to be a crucial component in a cover letter (Connor et al., 1995). All Canadian letters and all but one of the Taiwanese letters included this move. However, Taiwanese and Canadians adopted different strategies when expressing their desire for interviews. Taiwanese students used a form of direct or explicit request nearly 2.5 times more than Canadian students did. The most distinct direct statement produced by Taiwanese students was "Please consider my request for an interview." This sentence appeared in 15 (37.5\%) of the Taiwanese letters. This resembles Maier's (1992) study and indicates that nonnative English writers tend to use direct strategies in their writing more than native English writers do. The most common strategy for Canadian students in requesting an interview was to show an optimistic attitude, by using phrases such as "look forward to" or words such as "hope."

Another apparent difference between Canadian and Taiwanese writers in this move is the use of qualifying modals including "could," "may," "might," and "would." The function of qualifying modals is to lower the level of the speaker to that of the listener (Celce-Murcia \& Larsen-Freeman, 1999; Upton \& Connor, 2001). In the Canadian letters, the uses of "would," "might," and "may" outnumbered those same uses in the Taiwanese letters. The use of the first person "I" with "will" refers to the future intention of the speaker. In the corpus, Taiwanese students used more samples in formulas such as "I will contact you" or "I will be calling you" to express their intentions to contact the prospective employer. These types of sentences may appear too aggressive or may place pressure on the employer. Canadians used the phrases "I will be looking forward to" and "I will be available" to express their desire for an interview. These observations reveal that Taiwanese and Canadian students interpret the function of modal verbs differently. Another possible explanation is that Taiwanese students are unfamiliar with the use of modal verbs in English writing, either because their native language does not use modal verbs or because they do not understand their function in English. The following are examples that further illustrate this claim.

13. Please consider my request for an interview to discuss my qualification further. (Taiwanese \#25)

14. I will contact you in the near future to arrange a convenient time to meet you. (Taiwanese \#31)

15. I would value an opportunity to meet with you to discuss the ways in which I might contribute to the ongoing success of your team. (Canadian \#2) 
16. I look forward to speaking with you about this employment opportunity. (Canadian \#38)

\section{M5: Expression of Politeness or Appreciation}

The applicant typically closes the cover letter with a polite ending. Although not every letter in the Taiwanese corpus contained a move of gratitude (M5), all Canadian letters did. Canadian letters also used considerably more words to show their appreciation to the prospective employer than did the Taiwanese letters. Most M5 moves appear at the end of the letter along with the M4 move (i.e., expressing a desire for an interview). The major difference between Taiwanese and Canadian letters is in the Taiwanese lack of variety of expression and the predominance of the common formulaic closing of "Thank you + for + reasons." Specifically, 27 Taiwanese letters $(67.5 \%)$ provided this expression, whereas 19 Canadian letters (47.5\%) expressed this formulaic closing. With regard to thanking word usage, over $70 \%$ of Taiwanese used "thank/thanks" to express their appreciation, whereas $12(30 \%)$ Canadian samples used "appreciate" and 7 (17.5\%) samples used "value" for showing appreciation. Taiwanese students are likely unfamiliar with the uses of "appreciate" and "value." Consequently, they tend to solely use the words "thank/thanks" to show gratitude. The results are similar to those obtained by Cheng and Kuo (2011), which showed that nonnative speakers tend to use formulaic expressions and the words "thank/thanks" explicitly while showing appreciation.

The following examples illustrate the differences between the Canadian and Taiwanese writers in this regard.

17. Thank you for your time and consideration. (Taiwanese \#3)

18. Thank you for reviewing my résumé. (Taiwanese \#11)

19. I would appreciate you considering me for this position. (Canadian \# 8)

20. Once again I valued the time you have taken out of your schedule to read my application. (Canadian \#22)

\section{Conclusion}

We analyzed 80 internship cover letters written by Canadian and Taiwanese students and identified similarities and differences in linguistic features and rhetorical strategies between the two groups. In addition, cross-cultural variations regarding the patterns of move structures were observed. Despite the cultural variations, move structures employed by both groups possessed similar communicative functions. Although the cover letter is not a genre familiar to Taiwanese people, they attempted to conform to the standards associated with this professional genre and successfully employed essential moves in their cover letters to reach the communicative goal.

The results reveal certain differences in the surface-level linguistic features between the writings of the two groups. Canadians tend to write lon- 
ger letters, use a greater variety of word types and sentence structures, and choose more professional words than nonnative Taiwanese students do. Based on the move analysis, major differences were observed. To achieve the main communicative purpose of the cover letter, which is to be contacted for an interview, the Canadian students employed lengthy sentences and various strategies to demonstrate their qualifications (M3a, M3b, and M3c). They attempted to convince the prospective employer that they possessed the relevant academic and professional experience. Therefore, more information was presented in this move, which confirms earlier research showing that native writers are likely to employ more words in cover letters to describe their qualification than nonnative writers do (Connor et al., 1995). Taiwanese students, by contrast, tended to write short and general statements to present their qualifications and thus used the M3a move almost exclusively. They likely believed that the prospective employer would determine their qualifications from the résumé, and self-appraisal is mostly regarded unfavorably in Taiwanese culture. These students thus missed the opportunity to promote themselves in the cover letter. Therefore, Taiwanese writers seldom adopted $\mathrm{M} 3 \mathrm{~b}$ and M3c moves in their letters.

Taiwanese writers demonstrated tendencies to include other communicative elements that did not appear in the Canadian corpus. For example, to obtain interview opportunities, the Taiwanese heavily employed a direct strategy to express their desire for an interview. In addition, they also used formulaic expressions in their letters to meet particular communicative goals. In an attempt to write in an unfamiliar genre, nonnative speakers tend to include formulaic expressions discovered in their English textbooks. This shortcut approach might hinder their potential in writing a successful letter that describes their qualifications. The Taiwanese also use modal verbs differently than do Canadians. These writing strategies demonstrated by the Taiwanese students are likely caused by a lack of rhetorical knowledge regarding the cover letter, its purpose, and the process employed in creating an effective letter. However, the differences in these features may not be considered a major factor in creating communication barriers.

By adopting Upton and Connor's (2001) framework, this study produced similar research outcomes as those in previous studies (Al-Ali, 2004, 2006; Bhatia, 1993; Connor et al., 1995; Maier, 1992; Upton \& Connor, 2001). The findings suggest that move structural and rhetorical differences derive from the differences in writers' cultural backgrounds and their rhetorical and lexical knowledge of the particular genre. As Connor (2004) suggested, culture is crucial among these factors in contrastive rhetorical analysis. Thus ESL and EFL teachers and curriculum designers should be aware of how cultural preferences can influence learners' general learning patterns. The following considerations demonstrate how to incorporate the research method and data into the practical teaching of cover letter writing, particularly for nonnative English speakers. 
1. The instructor should clearly explain the purposes, communicative functions, structures, and forms of specific genres. In addition, linguistic features and technical vocabulary should be taught.

2. Students should be encouraged to analyze the textual structures by adopting move analysis strategies. They should be able to identify the differences between their own and native-speaker writing samples regarding move structures.

3. Students should be able to summarize the most frequently used moves in sample letters and compare the linguistic differences among these expressions (i.e., students should be able to recognize the moves that involve expressions of politeness or provide arguments).

4. Instructors should provide students with helpful material such as frequency lists of verbs or lexical bundles collected from cover letter corpora in other student disciplines and encourage students to use these words or phrases in their writing.

5. Instructors are encouraged to build and integrate cross-cultural corpora into their writing classes, through which students can become autonomous learners and thus learn to write by analyzing examples of effective writing.

Based on the study results, we suggest that students be taught practical writing skills by fully applying authentic language forms and cultural knowledge. Additional research can be conducted to include writing forms in other disciplines to develop appropriate instructional methods in teaching specific languages. A large corpus could also be constructed for future studies to obtain results that are more meaningful than those obtained in our study; the findings of this study may be constrained because of the small size of the corpora. The results reveal that a genre- and corpus-based approach can be used to further explore the writing strategies of native and nonnative speakers. Future studies could follow this model to provide helpful suggestions for curriculum design and material development.

\section{Acknowledgements}

This study was presented at the British Columbia TEAL (Teachers of English as an Additional Language) 2012 annual conference in Canada. Registration and participation expenses were funded by a grant from the National Science Council of Taiwan (Grant number: 1010018114).

\section{The Author}

Dr. Hsiao-I Hou obtained her Master's degree in TESL from McGill University and her PhD from the University of Minnesota. She has worked as a full-time assistant professor at National Kaohsiung University of Hospitality and Tourism in Taiwan. Her research interests include corpus linguistics and English for specific purposes. 


\section{References}

Al-Ali, M. N. (2004). How to get yourself on the door of a job: A cross-cultural contrastive study of Arabic and English job application letters. Journal of Multilingual and Multicultural Development, 25(1), 1-23.

Al-Ali, M. N. (2006). Genre-pragmatic strategies in English letter-of-application writing of Jordanian Arabic-English bilinguals. International Journal of Bilingual Education and Bilingualism, 9(1), 119-139.

Atkinson, D. (1999). TESOL and culture. TESOL Quarterly, 33(4), 625-654.

Belcher, D., \& Connor, U. (Eds.). (2001). Reflections on multiliterate lives. Clevedon, UK: Multilingual Matters.

Bhatia, V. K. (1993). Analysing genre: Language use in professional settings. London, UK: Longman.

Brusaw, C. T., Alred, G. J., \& Oliu, W. E. (1987). The business writer's handbook. New York, NY: St. Martin's Press.

Celce-Murcia, M., \& Larsen-Freeman, D. (1999). The grammar book: An ESL/EFL teacher's course. Boston, MA: Heinle \& Heinle.

Cheng, S. W., \& Kuo, C. (2011). A pragmatic analysis of MA thesis acknowledgments. Asian ESP Journal, 7(3), 29-58.

Connor, U. (2004). Intercultural rhetoric research: Beyond texts. Journal of English for Academic Purposes, 3(4), 291-304.

Connor, U. (2008). Mapping multidimensional aspects of research: Reaching to intercultural rhetoric. In U. Connor, E. Nagelhout, \& W. Rozycki (Eds.), Contrastive rhetoric: Reaching to intercultural rhetoric (pp. 299-315). Philadelphia, PA: John Benjamins.

Connor, U., Davis, K., \& De Rycker, T. (1995). Correctness and clarity in applying for overseas jobs: A cross-cultural analysis of U.S. and Flemish applications. Text, 15(4), 457-475.

Coxhead, A. (2000). A new academic word list. TESOL Quarterly, 34(2), 213-238.

51 Job News. (2010). Cover letter writing. Retrieved from http://big5.51job.com/gate/big5/ arts.51job.com/arts/76/352470.html

Flower, L., \& Hayes, J. R. (1981). A cognitive process theory of writing. College Composition and Communication, 32(4), 365-387.

Friedlander, A. (1990). Composing in English: Effects of a first language on writing in English as a second language. In B. Kroll (Ed.), Second language writing: Research insights for the classroom (pp. 109-125). Cambridge, UK: Cambridge University Press.

Henry, A., \& Roseberry, R. L. (2001). A narrow-angled corpus analysis of moves and strategies of the genre: "Letter of Application." English for Specific Purposes, 20(2), 153-167.

Hou, H.-I., \& Li, M.-Y. (2011). A contrastive rhetoric analysis of internship cover letters written by Taiwanese and Canadian hospitality majors. International Journal of Linguistics, 3(1), 43-57.

Jenkins, S., \& Hinds, J. (1987). Business letter writing: English, French, and Japanese. TESOL Quarterly, 21(2), 327-349.

Kaplan, R. B. (1966). Cultural thought patterns in inter-cultural education. Language Learning, $16(1-2), 1-20$.

Kroll, B. (Ed.). (2003). Exploring the dynamics of second language writing. New York, NY: Cambridge University Press.

Kurman, J. (2001). Self-enhancement: Is it restricted to individualistic cultures? Personality and Social Psychology Bulletin, 27(12), 1705-1716.

Maier, P. (1992). Politeness strategies in business letters by native and non-native English speakers. English for Specific Purposes, 11(3), 189-205.

Matsuda, P. K. (2006). The myth of linguistic homogeneity in U.S. college composition. College English, 68(6), 637-651.

Mohan, B. A., \& Lo, W. A.-Y. (1985). Academic writing and Chinese students: Transfer and developmental factors. TESOL Quarterly, 19(3), 515-534. 
Reichelt, M. (2011). Foreign language writing: An overview. In T. Cimasko \& M. Reichelt (Eds.), Foreign language writing instruction: Principles and practices (pp. 3-21). Anderson, SC: Parlor Press.

Reichelt, M., Lefkowitz, N., Rinnert, C., \& Schultz, J. M. (2012). Key issues in foreign language writing. Foreign Language Annals, 45(1), 22-41.

Scollon, R. (1997). Contrastive rhetoric, contrastive poetics, or perhaps something else? TESOL Quarterly, 31(2), 352-358.

Sedikides, C., Gaertner, L., \& Toguchi, Y. (2003). Pancultural self-enhancement. Journal of Personality and Social Psychology, 84(1), 60-79.

Sinclair, J. (1991). Corpus, concordance, collocation: Describing English language. Oxford, UK: Oxford University Press.

Spack, R. (1997). The rhetorical construction of multilingual students. TESOL Quarterly, 31(4), 765-774.

Swales, J. M. (1990). Genre analysis: English in academic and research settings. Cambridge, UK: Cambridge University Press.

Swales, J. M. (2004). Research genres: Explorations and applications. Cambridge, UK: Cambridge University Press.

Taillefer, G. F. (2005). Foreign language reading and study abroad: Cross-cultural and crosslinguistic questions. Modern Language Journal, 89(4), 503-528.

Upton, T. A., \& Connor, U. (2001). Using computerized corpus analysis to investigate the textlinguistic discourse moves of a genre. English for Specific Purposes, 20(4), 313-329.

Zamel, V. (1997). Toward a model of transculturation. TESOL Quarterly, 31(2), 341-352. 